\title{
Analysis of the Influence of Mechanical Couplings in Laminate Beams on the Adherence of the Assumed Boundary Conditions in the DCB Test Configuration
}

\author{
Jakub Paśnik $^{1, a^{*}}$, Sylwester Samborski, ${ }^{1, b}$, Jakub Rzeczkowski, ${ }^{1, c}$ and \\ Katarzyna Słomka ${ }^{1, d}$ \\ ${ }^{1}$ Lublin University of Technology, Department of Applied Mechanics, 20-618 Lublin, \\ Nadbystrzycka 36 St., Poland \\ a jakub.pasnik@pollub.edu.pl, bs.samborski@pollub.pl, ckubarzeczkowski@op.pl, \\ dkatarzyna.slomka@onet.com.pl
}

Keywords: Composite Laminate, Finite Element, Delamination, Double - Cantilever Beam, VCCT

\begin{abstract}
This paper shows numerical analyses of delamination in coupled laminates using finite element method. With increasingly wide spreading use of laminate composites a research development of those materials goes on. It is a common knowledge that the main form of damage in composites is delamination that is a loss of cohesion between neighboring layers. The main aim of the conducted research is to obtain the strain energy release rate (SERR) distributions along initial delamination front and verifying compliance of experimental and numerical analyses. Some analyses were performed using numerical models based on the double cantilever beam (DCB) test configuration, because it allowed to determine the values of SERR in mode I, G . The analyses were carried out using the Abaqus/CAE finite element software environment. Models of the specimens to be tested experimentally were elaborated in accordance with the DCB test configuration for which the boundary conditions and the load were specified. To model delamination process in composite beams the virtual crack closure technique (VCCT) was used [1]. In addition, numerical analyses of the boundary conditions and the laminate stacking sequence effect on the SERR distribution were done [1]. What is more, experimental analyses of crack shape were carried out. The results were obtained for two kinds of coupled layups: bending - extension and bending - twisting, as well as for uncoupled specimens and were compared mutually: the coupled and the uncoupled layups. The results of tests showed significant influence of boundary conditions and laminate stacking sequence both on the $\mathrm{G}_{\mathrm{I}}$ distribution along delamination front and on the crack front shape. It was noted that couplings have considerable impact on both numerical analyses' results and can induce unwanted deformations of the test specimens during physical experiments. Moreover, crack shapes in numerical models and in experimental specimens were compared.
\end{abstract}

\section{Introduction}

Composite materials are being increasingly used as construction materials. They can often be a substitute of conventional materials, such as steel or aluminum, used for making specific construction elements. What is it that distinguishes these materials from a wide range of materials? These are in particular their specific characteristics. Composites are the materials that contain two components called phases: the matrix phase and the reinforcing phase (in this instance - fibers). The matrix is supposed to connect elements of reinforcing phase and to retain some specified fibers orientation in the whole volume of element. The reinforcing phase can take form of fibers or molecules. Due to combination of two materials of significantly different 
parameters, a new material has extraordinary parameters which are impossible to obtain in conventional materials. The main advantage of laminate composites, which are considered in this paper, is great toughness with relatively low weight. When one compares use of composite material with use of steel or aluminum, he will notice not only better durability but primarily significant weight reduction of designed element. And these all advantages determine use such materials in range of industrial sectors such as: automotive, aviation, aerospace, civil engineering but also as components of sport equipment [4]. A wide range of application of composites requires precise research on parameters of these materials, mechanisms and terms of damage. This paper is to analyze the most common damage in laminate composites - delamination, which is loss of cohesion between neighboring layers. There were elaborated three modes to study conditions of fracture propagation in construction materials, they are schematically shown in fig. 1 .
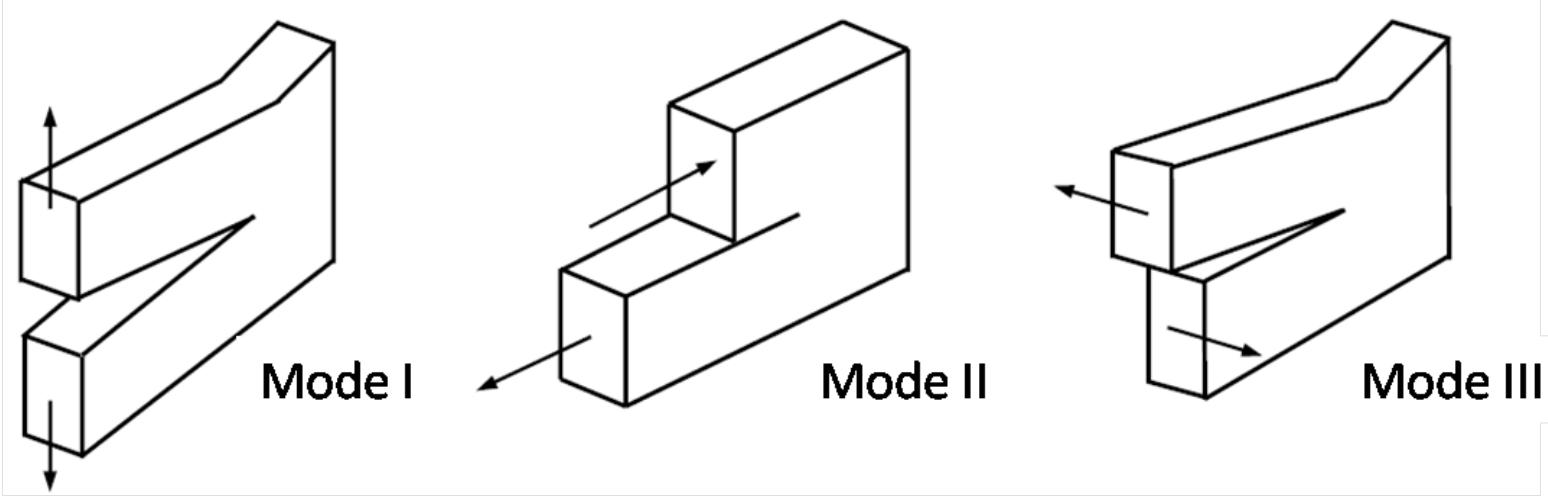

Fig. 1. Fracture modes

\section{Parameters of tested beams}

This paper shows numerical and experimental analyses of specimens made out of laminate composite of the commercial name SEAL Texipreg HS160RM. Material characterization is shown in Table 1.

The specimens used for tests were prepared precisely. Beams were made out of prepregs in the shape of unidirectional reinforcement. Single carbon-epoxy ply thickness was $0,1 \mathrm{~mm}$, and glass ply thickness equals 16 carbon-epoxy plies thickness. In tested beams initial crack was introduced by implementing PTFE foil between two branches of specimen on the length of $65 \mathrm{~mm}$ (Fig. 2). In order to make crack front shape visible (in experiment), white paint was injected pressurized beetwen separated branches. Paint was supposed to fill crack and show how far crack front went during test. To observe crack front shape, two branches of beam was separated completely which made it possible to monitor crack shapes. 
Table 1. Material properties

\begin{tabular}{|c|c|c|c|c|c|}
\hline \multicolumn{6}{|c|}{ Basic material constants } \\
\hline $\begin{array}{c}\mathrm{E}_{1} \\
{[\mathrm{MPa}]}\end{array}$ & $\begin{array}{l}\mathrm{E}_{2}=\mathrm{E}_{3} \\
{[\mathrm{MPa}]}\end{array}$ & $\begin{array}{c}v_{12}=v_{13} \\
{[-]}\end{array}$ & $\begin{array}{l}v_{23} \\
{[-]}\end{array}$ & $\begin{array}{c}\mathrm{G}_{12}=\mathrm{G}_{13} \\
{[\mathrm{MPa}]}\end{array}$ & $\begin{array}{c}\mathrm{G}_{23} \\
{[\mathrm{MPa}]}\end{array}$ \\
\hline 109000 & 8819 & 0,342 & 0,380 & 4315 & 3200 \\
\hline \multicolumn{6}{|c|}{ Fracture mechanics constants } \\
\hline $\begin{array}{c}\mathrm{G}_{\mathrm{Ic}} \\
{[\mathrm{N} / \mathrm{mm}]}\end{array}$ & & $\begin{array}{c}\mathrm{G}_{\mathrm{Iic}} \\
{[\mathrm{N} / \mathrm{mm}]}\end{array}$ & $\begin{array}{c}\mathrm{G}_{\text {IIIc }} \\
{[\mathrm{N} / \mathrm{mm}]}\end{array}$ & & $\begin{array}{c}\eta \\
{[-]}\end{array}$ \\
\hline 0.4 & & 0.8 & 0.8 & & 1.62 \\
\hline
\end{tabular}

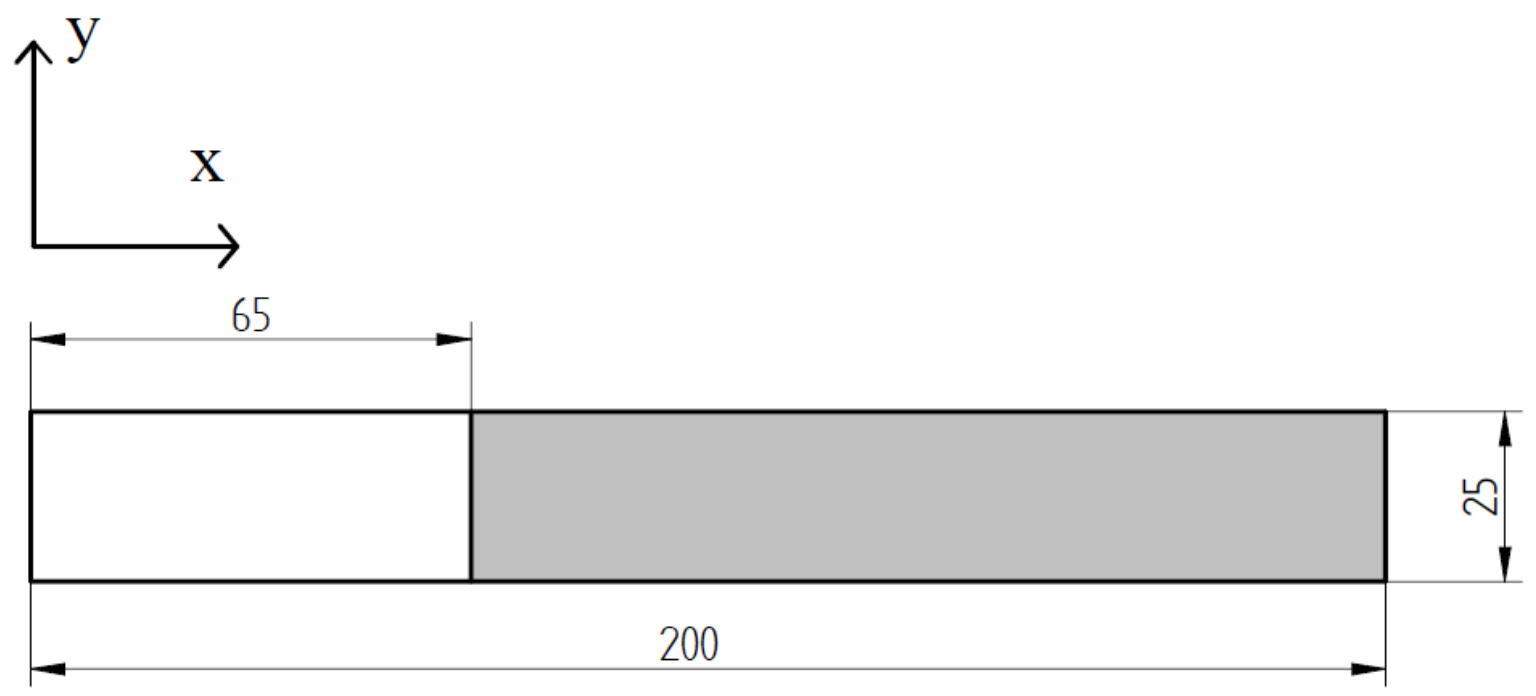

Fig. 2. Initial crack length

\section{Numerical modeling technique}

Experimental research results were confronted with results obtain in numerical tests. The numerical analyses have been performed in the Abaqus/CAE finite element software environment. Utilization on such software made it possible to make numerical model of the beam and conduct simulations reflecting actual experimental tests. Geometric model of laminate was prepared as a shell element to which composite layups was implemented in Property module. Specimen was tested in mode I with boundary condition reflecting double cantilever beam [1]. Boundary condition and loading of the beam was presented schematically on fig. 3. 
Edge 1-2-3 of lower branch was not able to move - all degrees of freedom were disabled. To edge 4-5-6 vertical displacement $\delta$ was attached along $z$ axis. The other degrees of freedom were also disabled with exception of rotation along $y$ axis.

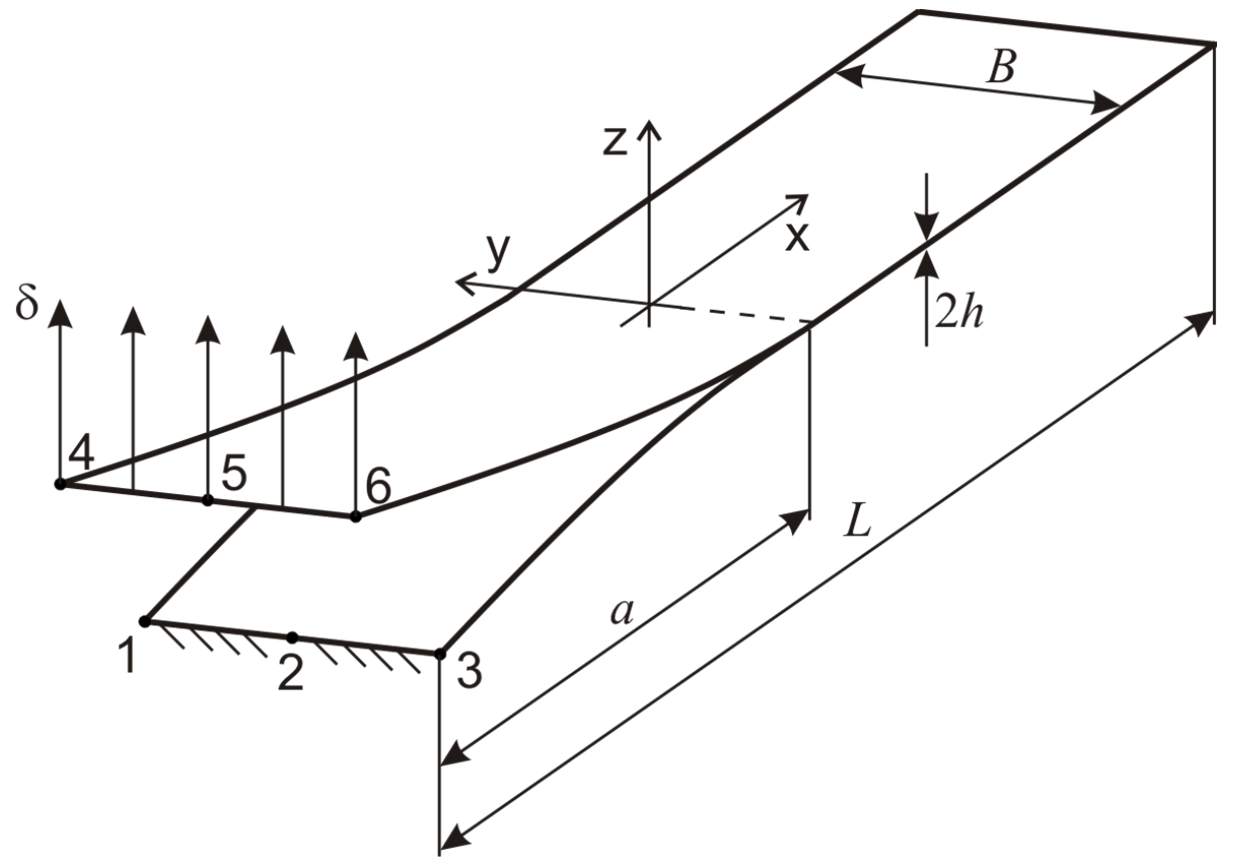

Fig. 3. Boundary conditions and loading [1]

With the translation vector defined as $u_{i}$ and rotation as $\theta_{i}$, boundary conditions can be submitted as:

$$
\begin{gathered}
u_{i x}=u_{i y}=u_{i z}=\theta_{i x}=\theta_{i z}=0-\text { for } 1-2-3 \text { edge } \\
u_{i x}=u_{i y}=\theta_{i x}=\theta_{i z}=0, u_{i y}=\delta-\text { for } 4-5-6 \text { edge. }
\end{gathered}
$$

Numerical model of the beam is made out of two parts connected with surface-to-surface contact in Interaction module. Interaction properties were shown in table 1 . To avoid convergence problems, small distance was implemented between parts with Clearance option. Each instance was meshed with elements with size of approx. $2 \mathrm{~mm}$. However, area where delamination was supposed to occur and near the beam's edges was divided on more elements with size of 0,5 mm. Such mesh density was relevant impact of numerical results. Elements types used in simulation were S4 near delamination front and S4R where propagation was not expected.

For delamination analysis Virtual crack closure technique (VCCT) was used. As fracture criterion the Reeder Law has been chosen [3]:

$$
G_{e q-c}=G_{I c}+\left(G_{I I}-G_{I}\right)\left(\frac{G_{I I}+G_{I I I}}{G_{T}}\right)^{\eta}+\left(G_{I I I c}-G_{I I c}\right)\left(\frac{G_{I I I}}{G_{I I}+G_{I I I}}\right)\left(\frac{G_{I I}+G_{I I I}}{G_{T}}\right)^{\eta}
$$

where $\mathrm{G}_{\text {eq-c }}$ stood for equivalent critical strain energy release rate (SERR) 


$$
G_{T}=G_{I}+G_{I I}+G_{I I I}
$$

When $G_{T}$ exceeds $G_{\text {eq-c }}$ delamination occurs.

\section{Results and discussion}

In this paragraph results of numerical and experimental tests were presented.

The fig. 4 below presents crack front shapes in laminate composites. Crack front shapes obtainin numerical analyses and experimental testswas compared. As can be seen, both numerical and experimental analyses' results correspond with each other in specimens no. 1 and 2. Fronts have similar shapes for these tests. Although, specimens 3 and 4 tests give dissimilar results. Numerical analysis of beam no. 3 shows reverse curvature than experimental work does. In experimental test of specimen 4 on the other hand, there were some manufacturing error, which cause very unusual front shape. However, it should be noted that during tests, some unwanted effect occurs. It is when two branches did not separate completely during test and are still linked with partly separated, decussate fibers. And it is called bridging phenomenon.

In addition to that, SERR distributions along delamination front were obtained in FEM analyses.

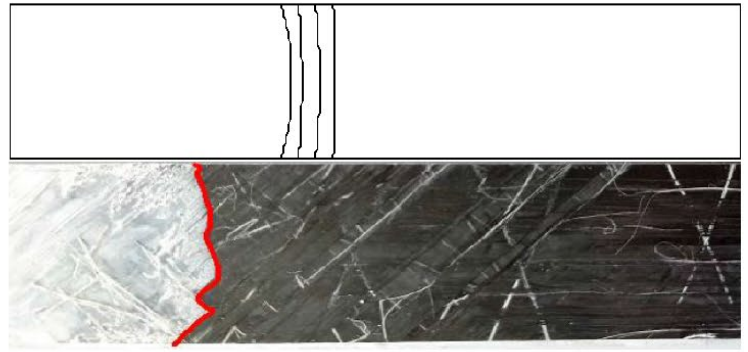

1. $[\mathrm{G} / 90 / 0 / 45||-45 / 0 / 90 / \mathrm{G}]$

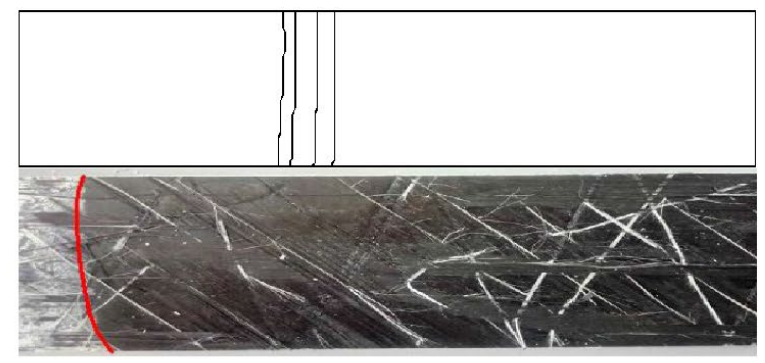

3. $[\mathrm{G} / 90 / 0 / 45|| 45 / 0 / 90 / \mathrm{G}]$

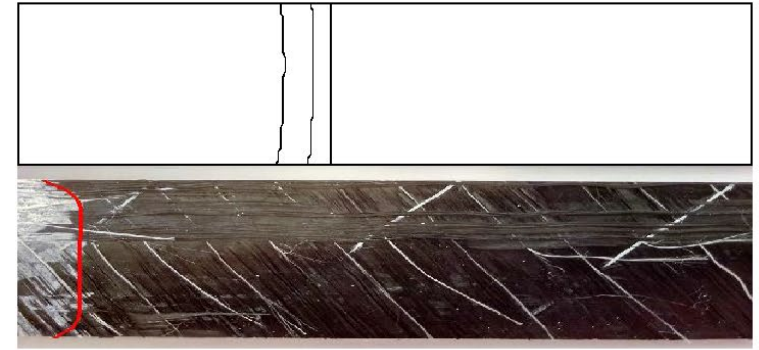

2. $[\mathrm{G} / 90 / 0 / 60|| 60 / 0 / 90 / \mathrm{G}]$

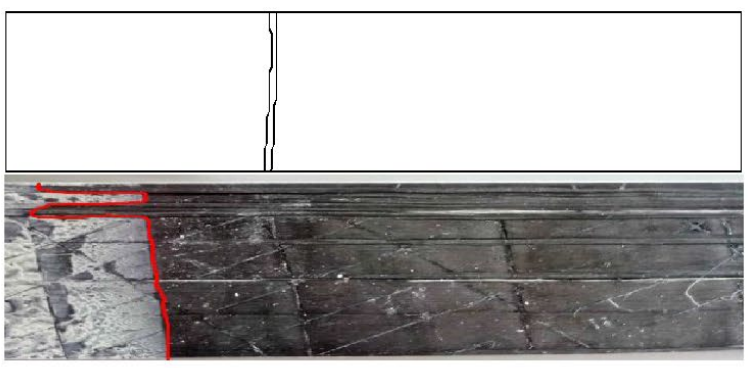

4. $[\mathrm{G} / 90 / 0 / 0|| 30 / 0 / 90 / \mathrm{G}]$

Fig. 4. Crack front shapes comparison 


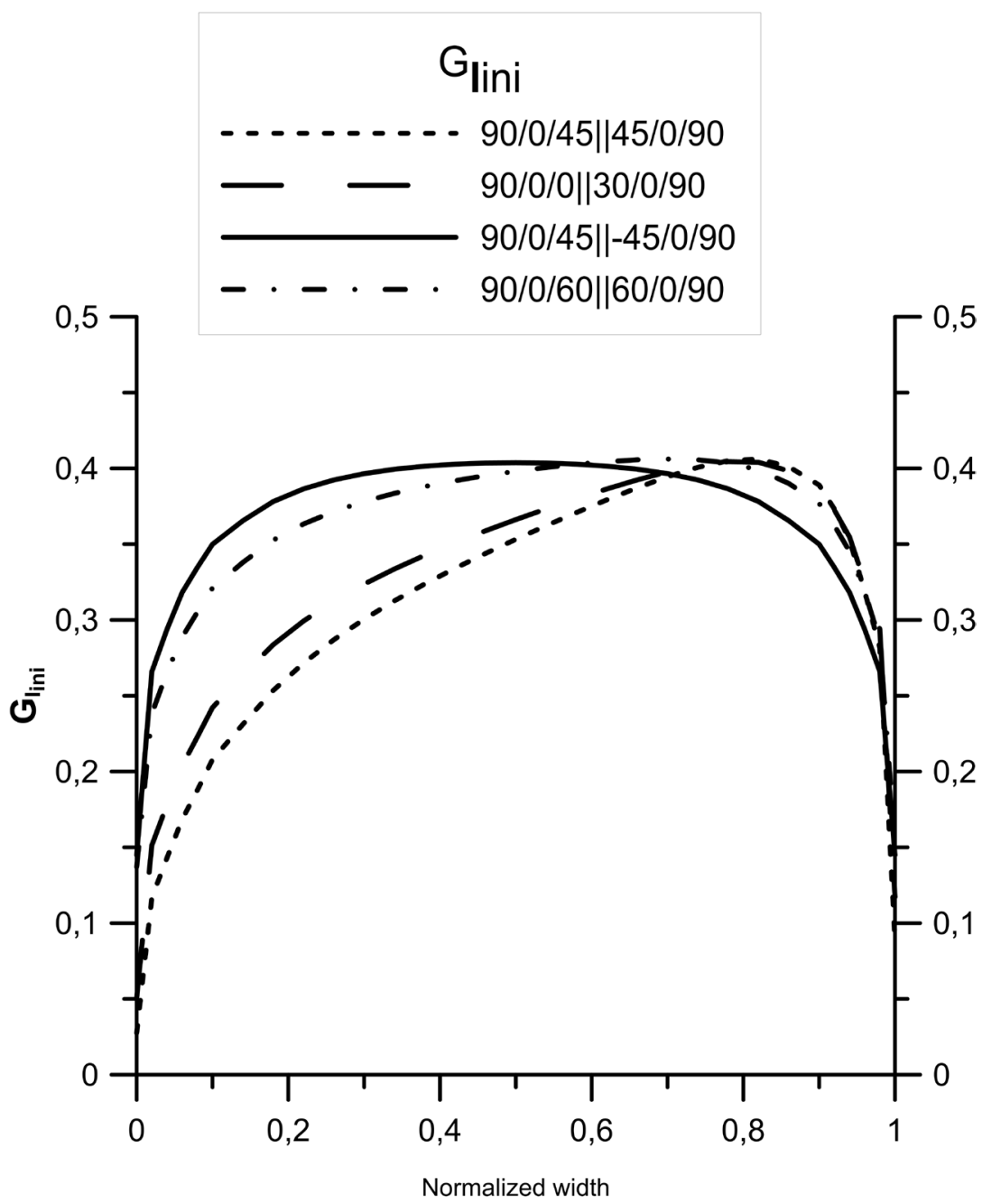

Fig.5 SERR distribution along delamination front

\section{Summary}

In this a paper comparison of numerical modeling results with experimental tests results in the field of crack front shape in laminate composites was presented. The results verified accuracy of using VCCT for modeling delamination with ABAQUS/CAE finite element environment. In addition to that, some problems which can appear in experimental tests were observed, such like bridging effect or some manufacturing errors. Numerical results in the form of crack front shapes and SERR distributions were verified in experimental test in different stacking sequences. Further research will aim to optimize numerical model and reduce impact of unwanted effects in experimental tests.

\section{Acknowledgements}

This paper was financially supported by the Ministerial Research Project No. DEC2016/21/B/ST8/03160 financed by the Polish National Science Centre.

\section{References}

[1] S. Samborski, Numerical analysis of the DCB test configuration applicability to mechanically coupled Fiber Reinforced Laminated Composite beams, Composite Structures 152 (2016) 477 487. https://doi.org/10.1016/j.compstruct.2016.05.060 
[2] S. Samborski, Analysis of the end-notched flexure test configuration applicability for mechanically coupled fiber reinforced composite laminates, Composite Structures 163 (2017) 342 - 349. https://doi.org/10.1016/j.compstruct.2016.12.051

[3] S. Samborski, J. Rzeczkowski, J. Paśnik, Issues of Direct Application of Fracture Toughness Determination Procedures to Coupled Composite Laminates, IOP Conference Series: Materials Science and Engineering, Volume 416 (2018) 012056. https://doi.org/10.1088/1757899x/416/1/012056

[4] J. Paśnik, S. Samborski, J. Rzeczkowski, Application of the CZM Technique to Delamination Analysis of Coupled Laminate Beams, IOP Conference Series: Materials Science and Engineering, Volume 416 (2018) 012075. https://doi.org/10.1088/1757-899x/416/1/012075

[5] C.B.York, Unified Approach to the Characterization of Coupled Composite Laminates: Benchmark Configurations and Special Cases, Journal of Aerospace Engineering 23(4) (2010). https://doi.org/10.1061/(asce)as.1943-5525.0000036

[6] M.F.S.F. De Moura, R.D.S.G. Campilho, J.P.M. Gonçalves, Crack Equivalent Concept Applied to the Fracture Characterization of Bonded Joints under Pure Mode I Loading. Composites Science and Technology 68 (2009) 2224. https://doi.org/10.1016/j.compscitech.2008.04.003

[7] V. Burlayenko, T. Sadowski, FE modeling of delamination growth in interlaminar fracture specimens, Budownictwo i Architektura 2 (2008) 95 - 109.

[8] J. German, Podstawy mechaniki kompozytów włóknistych, Wyd. PK, Kraków, 2001

[9] ABAQUS Online Documentation, Version 6.14,@ DassaultSystèmes, 2014. 